\title{
BUILDING CONDITIONS ASSESSMENT OF BUILT HERITAGE IN HISTORIC BUILDING INFORMATION MODELING
}

\author{
SILVANA BRUNO \& FABIO FATIGUSO \\ Department DICATECh, Politecnico di Bari, Italy
}

\begin{abstract}
The article concerns the implementation of the HBIM approach (Historic Building Information Modeling) for the refurbishment and preservation of historic buildings. The scientific and technical community confirmed the efficacy of BIM tools for knowledge managing and sharing, still noting a limited research of Building Conditions Assessment in HBIM. Starting with observed criticalities and potentialities, we propose a method for sharing and re-using information acquired through archival analysis, damage survey and diagnostic investigation. Therefore, we formalize the information requirements as input in BIM model and sharing modes for project and construction management.

Keywords: ancient masonry, building conditions assessment, diagnostics, HBIM, historic building
\end{abstract}

\section{INTRODUCTION}

The coherent and effective refurbishment of historic buildings outcomes from the solid knowledge as acquired during the diagnostic phase. The handover of the information still happens in form of papers or files among professionals, and generally, the interpretation of data, for diagnosis and Building Conditions Assessment (BCA), occurs as independent activity without an organized discussion between stakeholders. The complete integration of parties involved (data and actors) needs the configuration of lean workflows for exchanging structured data via automatic steps, enhancing the interoperability between applications.

When planning structural consolidation, decisions stand on the assessment of structural safety in order to implement risk reduction strategies. Indeed, energy retrofits require diagnosis of residual thermal performance of building envelopes and mechanical devices. This assessing phase of refurbishment project develops in different steps; the preliminary ones consist in the creation of a knowledge framework based on geometric surveys, analysis of material/ construction techniques and typological studies conducted from historical and photographic records, archival documentation and prior drawings. Simultaneously, a more specific diagnosis about materials/constructive characterization and damage and risk conditions is executed via traditional and augmented visual inspection, assisted by laboratory and in situ tests. The 3D laser scanning and photogrammetry might work as innovative techniques for augmented visual inspection, improved by the use of Unmanned Aerial Vehicles (UAV), and for acquiring dense and accurate points clouds and digital images with high resolution from which generate 3D models $[1,2]$. The execution of diagnostic tests consolidates or refutes formulated hypothesis about building conditions [3, 4]. For instance, the comparison of GPR and Infrared Radiation (IR) thermography results assists the recognition of constructive techniques and actual conservation of structural elements. Nevertheless, the difficulties in collating independent analysis - carried out by different members of the team project and derived from several sources - return challenging comparison of diverse data, with negative effects on planning refurbishment interventions.

These issues rise when the historic artefact has structural multi-wythe masonry walls, made from different materials, and the historic building underwent several restoration 
interventions along time, because of material degradation, collapse and/or typological transformation for changing building utilizations. In this perspective, an innovative methodology might support the collation, coordination and sharing of incremental knowledge derived by the entire set of acquired information.

The implementation of the Building Information Modeling can represent an approach for improving collaboration, trying to reduce fragmentation [5-7]. As concept of a repository [8], BIM links different tools and permits queries about building condition, time scheduling, and cost estimation to design adequate and sustainable interventions. In addition, it provides graphical views, documentations and parametric information available over the entire life cycle of the building. The specific usage of the BIM approach for the refurbishment and maintenance of historic buildings assumes, in literature, several denominations. Firstly, Murphy et al. 2013 [9] introduced the Historic Building Information Modeling, and then proposed as Historic Building Information Modeling and Management [10]. Nevertheless, Volk et al. 2014 [11] identified a still limited implementation of BIM in existing buildings, in the specific about cause-effect and deterioration modeling, deviation modeling or uncertainties. To produce these advancements in the methodology, a structured and integrated HBIM model as database of semantic information has been proposed [12].

The integration of the diagnostic data within a BIM-aided refurbishment is an ongoing topic, because of the significance for a complete architectural framework of the artefact. In literature, the first attempts generally regard the use of thermo-graphic images and monitored temperature and humidity via Building Energy Management Systems (BEMS) for energy analysis, and GPR for roads rehabilitation [12]. The elaborated thermic pictures reproduce the $3 \mathrm{D}$ as-is building energy modelling to simulate the real thermal performances for energy retrofits, considering the actual thermal properties, reduced by material degradations [13]. The GPR tests identify utilities under the road surfaces to prevent damage risks [14].

The purpose of this paper is including results acquired via georadar and endoscopy into an existing drilling hole, executed on a masonry wall of an ancient building in southern Italy.

\section{METHODOLOGY}

The work aims at the investigation about (1) acquiring information for refurbishing existing buildings, (2) structuring and collecting knowledge in order to reduce fragmentation and improve collaboration and (3) sharing and making effective project decisions.

A possible approach is shown in this paper, proposing next developments of the methodology through algorithms for comparing results from different sources and utilizing them for supporting decisions, entirely within the BIM approach. This work utilizes a simplified and conceptual BIM model in Revit Autodesk for collecting images, comments, parameters provided by interpreting diagnostic results. The data are included as structured object attributes, organized into specific property sets, with a proper data type (number, length, area, but also text, enumeration, URL and pictures, etc.).

Inserting this data as structured information permits to manage a master database thought the BIM model, in turn employed as flexible tool for innovatively producing traditional dossiers and drawings limiting time for reporting modifications to the different documentation (thus coordinated and congruent), and errors because of bidirectional links among model, database, views and schedules. The limitation occurs when employing the BIM model for specific analysis, identifying problems in direct export/import of some data in expert software products. Indeed, the immediate sharing and use of diagnostic data in construction site can be solved generating Virtual and Augmented Reality from the three-dimensional model, visualized on mobile devices. 
The case study presents the complexity of managing diagnostic data about masonry walls, made from heterogeneous materials without control tests, undergone several transformations.

\section{BUILDING CONDITIONS ASSESSMENT IN HBIM}

\subsection{Workflow of HBIM-aided refurbishment with diagnostic data}

As just clear, an important step for refurbishment of existing building, also within a BIM workflow, is the Building Conditions Assessment (BCA), before deciding the proper interventions [12]. Consequently, it is necessary to select tools and methods for reaching the objectives for acquiring an accurate knowledge (Fig. 1).

The BCA is done comparing information (measured data, comments, interpretation) acquired during preliminary in-situ investigations to identify masonry textures, decay patterns, damage and vulnerabilities of materials and structural elements.

Nowadays, the use of photogrammetric and topographic surveys supports the detection of deformations, out of plumb and kinematic mechanisms. Recent BIM approaches for Cultural Heritage investigated the potentiality of these methods for geometric, stratigraphic and structural damage survey [15-17]. While, other laboratory and in-situ tests, even if relevant for the continuous process of knowledge, do not still find a complete collocation in the HBIMaided refurbishment of historic buildings [12]. Generally, parametric BIM objects deliver geometric and materic data, excluding detailed information about the conservation status. The list of tests and techniques, illustrated below (Table 1), needs to be considered for further protocols within the BIM models and approaches:

Referring to the complete process of the HBIM-aided refurbishment, it comprehends the preliminary information collection, the reverse engineering for the creation of 'as-built/ as-damaged BIM', the Building Conditions Assessment (BCA) and the project itself [12].

For this last phase, the attributes inserted in the architectural model are useful for structural and/ or energy analysis, and filtering them into the specific software product might limit information losses, redundancies and inconsistencies reducing manual insertion, thus errors. Currently, filter and sharing these attributes can present difficulties of interoperability between architectural and structural/energy modeling tools, aspect deserving future investigations and software developments.

The design of structural consolidation of masonry or seismic upgrading interventions requests the material-constructive characterization, likewise the evaluation of mechanical parameters of materials. These quantitative data, influenced by decay, enter the Finite Elements

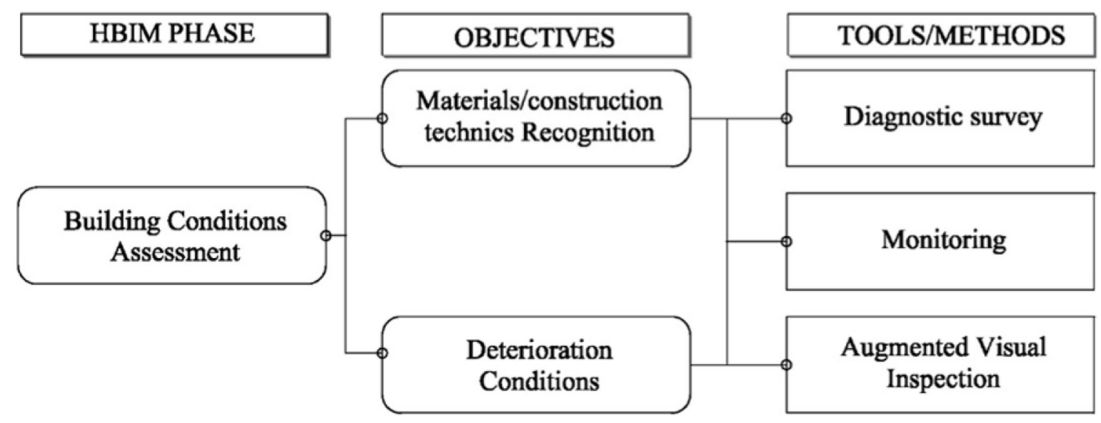

Figure 1: Framework about Building Conditions Assessment (Source: Authors.) 
Table 1: Destructive and non destructive survey and laboratory tests for the BCA.

\begin{tabular}{ll}
\hline Survey & Objectives \\
\hline Radar tests & $\begin{array}{l}\text { (a) vault, walls and slabs stratigraphy, (b) } \\
\text { presence of voids and cavities, (c) presence of } \\
\text { consolidation interventions }\end{array}$ \\
Video-endoscopy & $\begin{array}{l}\text { (a) stratigraphic study of structural elements } \\
\text { (monolithic elements, multiple layers), (b) pres- } \\
\text { Sonic and ultrasonic tests }\end{array}$ \\
$\begin{array}{l}\text { ence of cracks and cavities } \\
\text { (a) modal parameters (frequencies and modal }\end{array}$ \\
$\begin{array}{l}\text { sest of environmental vibration/ } \\
\text { Laboratory tests (axial compression }\end{array}$ & $\begin{array}{l}\text { (a) mechanical parameters (b) stress-strain curves } \\
\text { test, monotonic and cyclic type) }\end{array}$ \\
Finite Element analysis & (a) evaluation of the health and safety status of \\
& structures \\
\hline
\end{tabular}

Model (FEM) for simulating the structural behavior. Nevertheless, the complexity in obtaining real data, principally for masonry walls with anisotropic response, creates difficulties in performance modeling that rise if there are losses in information delivery.

The limitation of errors in estimating mechanical parameters (normal elastic modulus $(\mathrm{E})$ and shear modulus $(\mathrm{G})$, compressive strength $\left(\mathrm{f}_{\mathrm{m}}\right)$, shear strength $\left(\mathrm{t}_{0}\right)$ and average value of specific (w)), occurs with experimental tests on all the different types of masonry. The integration of weakly destructive and non-destructive tests permits to achieve this aim, avoiding further deterioration of the historic building and architectural components (i.e. frescoes surfaces and decorative apparatus). The thermo-graphic technique might detect masonry degradation and humidity patterns by monitoring superficial temperature. Punctual coring generally confirms the detected stratigraphy and typology of masonry. The weakly destructive tests with single and double jacks locally estimate stress and stiffness [18]. Non-destructive tests, such as radar and seismic tests, support the extension of the quantitative attributes on building structures with similar qualitative properties. Despite the importance of the BCA for refurbishment, there are no protocols, in literature, for inserting and managing diagnostic information (values of logged parameters, installation plan about instrumentation, methodology, images, diagrams, comments) in BIM approach.

\subsection{Available tools for knowledge managing and sharing in BIM approach}

The methods for managing and sharing information about refurbishment, made available during the entire life cycle of the historic building, might be classified in four main categories:

1. tool-to-tool for simulating and comparing building performance in the 'as-damaged' status and after modelling refurbishment interventions;

2. operative tools/methods for construction management (such as Virtual Reality (VR) and Augmented Reality (AR));

3. database for Facility Management and maintenance;

4. cloud-based services for diffusing knowledge about history and cultural characteristics. 
The first category consists in the use of (1) add-ons and plug-ins for direct connections between software products, based on Application Programming Interfaces (APIs) or (2) exchange formats, open (IFC specifications (IFC (*.ifc), IFCXML (*.xml), IFCZIP (*.ifczip), Coordinated View) or proprietary, within the same hierarchical proprietary platform or different ones.

The second class is represented by mobile versions of BIM tools for Virtual Reality (VR) and Augmented Reality (AR) technologies, for more effective real-time communication between employees and professionals, directly from the construction site. The development of connecting technologies between 2D/3D environments and the work site enhances cloudbased reporting of data, notes, checklists, and alerts via mobile devices [19].

In the specific, the integration of BIM and AR demonstrated potentialities for information retrieval and visualization, with the effect on reducing errors during executions of interventions, assemblies and equipment employment [20,21]. These aspects contribute to control planned costs and time scheduling with proactive actions for preventing such defects resulting by workload for manual and physical inspections of several building components, and data loss when updating project variations and defects [22].

The third category regards the Facility Management and maintenance that can take advantages both from AR, VR, and relational database connected with BIM models [23], and traditional FM systems such as CMMS (Computerized Maintenance Management System), EDMS (Electronic Document Management System) and BAS (Building Automation System) [23].

Finally, the knowledge re-use about history and cultural characteristics for touristic and educational purposes especially succeeds via computer vision technologies and web services platform to solve issues related to scalability and high size of BIM files [16, 24].

\section{CASE STUDY}

The research investigates a BIM workflow for BCA executed on a multiple-wythe masonry for managing diagnostic results to support decisions and control quality. In this specific case, diagnostic tests can be carried out for assessing the decay condition of masonry walls or for monitoring consolidation works, such as cement injection.

\subsection{Information requirements}

The preliminary investigations identified irregular transversal sections, different walls thickness at the same level and from the basement to the top. In the case study, the confirmation of information about stratigraphic composition, materials, and decay condition derives by diagnostic tests (georadar and endoscopic tests).

In a traditional approach, the reports of diagnostic tests and other documentation about the refurbishment project are separate paperwork that generate difficulties in retrieval data to plan interventions and program maintenance.

The investigation of capabilities of BIM approach in its current degree of development evidences the possibility to record data and metadata, provided by diagnostic tests and bibliographic research, into the parametric object as project properties, associated to object types or instances, and then structured in schedules, views and sheets.

The work is carried out on the walls modelled as 'Structural wall', with the scope of directly creating the analytic model for structural analysis, because the masonry walls present the double function of load bearing element and external envelope. Consequently, this 
decision costs the lack of information about the irregular geometry, in cross sections and along the total height. In the IFC standard, the wall type consists in IfcWallStandardCase.

The masonry types have been codified by an alphanumeric ID, composed by typology (multiple-wythe unit masonry: MultiWM, different from Single unit masonry: SM) and reference cardinal point. The structure of walls consists of three layers: external and internal leaves, composed by limestone bricks in regular shape, and the inner core in compact limestone masonry, according to the traditional, and local constructive technics.

Non-destructive diagnostic tests firstly provide multimedia or digital file (video, images, graphs), to be interpreted compiling textual comments or inserting integer/real values with its measurement unit in correspondence of physical properties (thickness, thermal and mechanical parameters) into the parametric objects. The information requirements, to place into the model in the temporal phase named 'as damaged', regard identity data, diagnostic data and physical properties. The lists of attributes is shown below (Table 2, Fig. 2):

Table 2: Project parameters into the parametric object Structural wall

Wall: Type/instance attributes

Type

MWUM_est/...

[Wall stratigraphic composition]_[Cardinal Point] MWUM (Multiple-Wythe Unit Masonry) or SM (Single Unit Masonry).

\section{Construction}

Structure

Show structure

Materials and finishings

Structural material

Masonry in rough-hewn limestone bricks.

\section{Identity data}

Keynote

URL

Description

$\mathrm{M}(=$ Walls $)$

About reports/technical sheets

Masonry in rough-hewn limestone bricks, horizontal and stagger vertical joints. Degradation of mortar in joints.

Assembly description

Ext. Wall.- Brick Cavity

Assembly code

According to national building product codification (i.e. Uniformat) B2010154

Deep Hole Drilling Acquisition

Hole drilling total.png

Deep Hole Drilling Comments

[CONFERMED] Cavities in limestone bricks for karst phenomena. Bricks thickness (Reference value): $30 \mathrm{~cm}$. Consolidated masonry. Nucleus: lime mortar and stone bulk, compact and cohesive. Transversal cross bricks.

Generic model: Type/instance attributes

Type

GPR_ProfileAA_L01

Naming type: GPR_Profile[ProfileCode $] L / T[n$ profile], Longitudinal/Transversal 
Table 2: (Continued)

\section{Text}

GPR Profile Code

\section{Data}

GPR_Acquisition File

GPR_Methodology

GPR_Equipment

GPR_Radar image

GPR_Comments
[ProfileCode]_L/T[n profile $]$

[ProjectName]/[yymmdd][ProfileCode].ZON

- Reference point for profile localization (height, distance);

- Number of longitudinal (L) and transversal (T) profiles;

- Distance among profiles;

- Total area investigated (for three-dimensional profiles)

Type of Acquisition Unit (IDS DAD FastWave, one channel, 16bit)

Type of antenna, Voltage and Frequency (Antenna IDS TR600V 2000MHz or 600HZ)

AA_L01_070.png

A hyperbola where the interface between air and deep drilling hole (about $1.30 \mathrm{~m}$ from the origin of the profile). Difficult identification of the horizontal line between the first layer and the core, probably caused by different thickness of bricks.

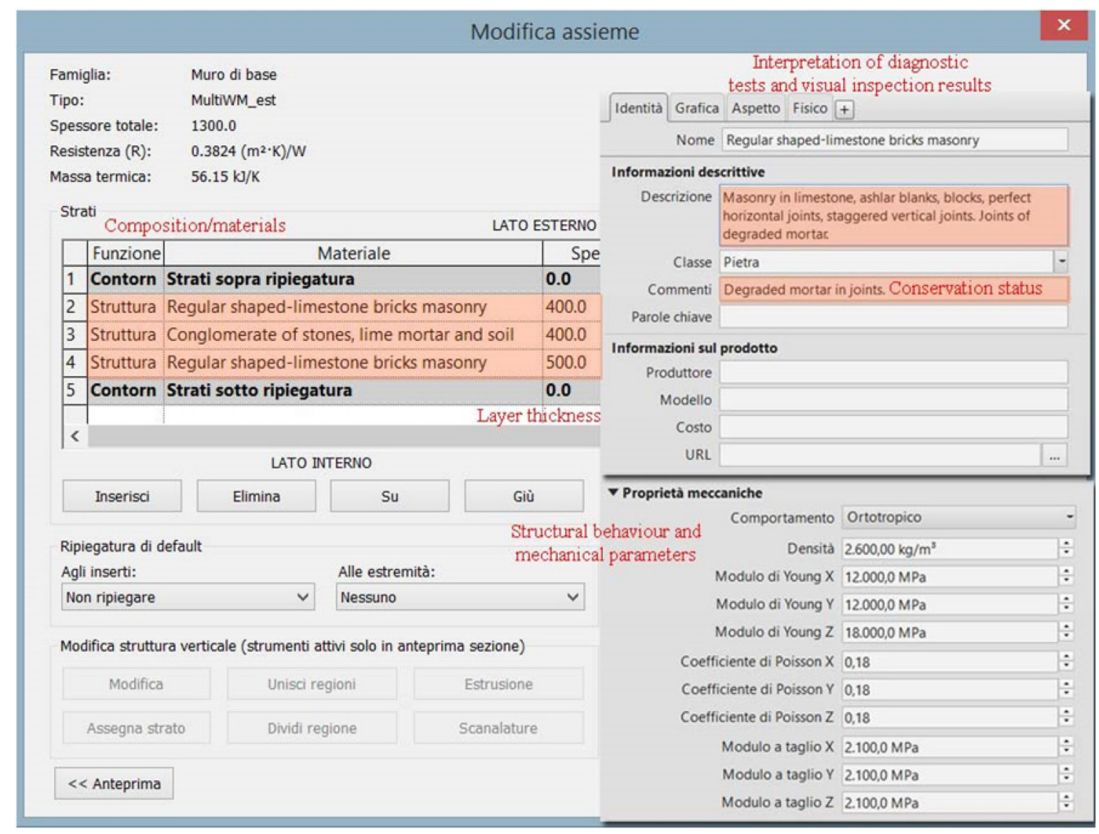

Figure 2: Insertion of quantitative data, derived from diagnostic tests, into the BIM wall (Source: Authors.) 


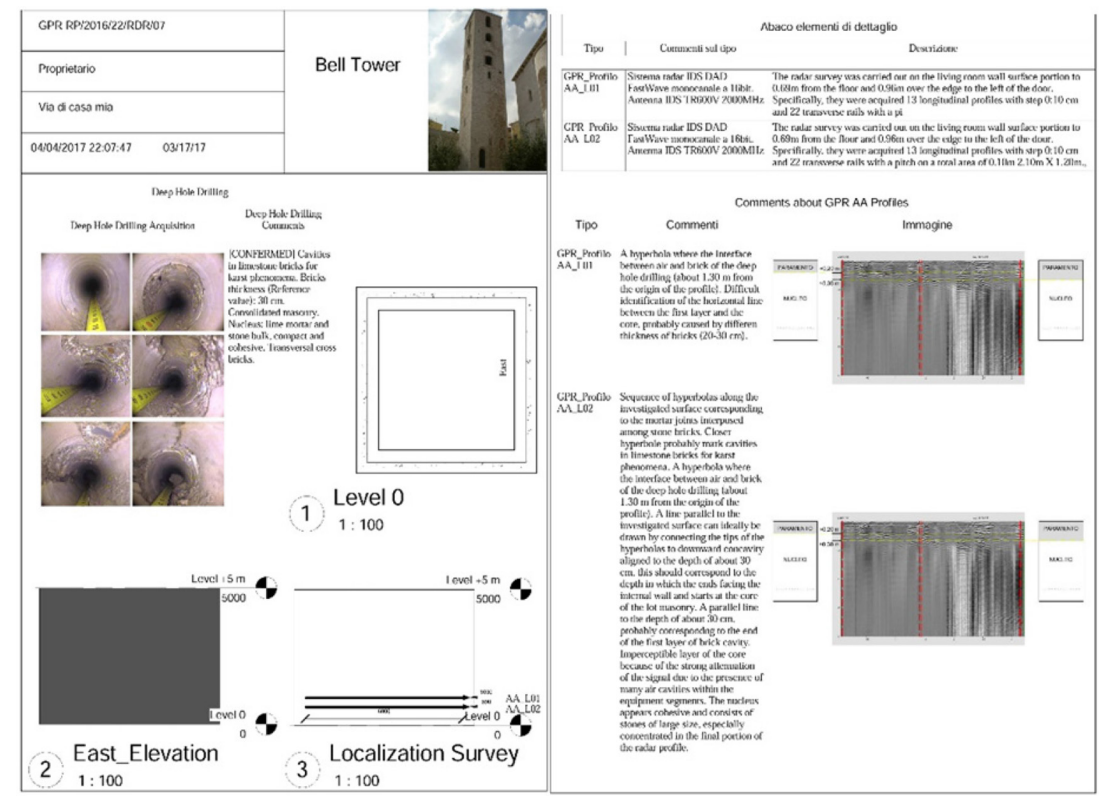

Figure 3: Diagnostic report (Source: Authors.)

The added attributes are employed as scheduling fields to organise diagnostic reports, useful to collect images, data and comments in digital sheets (Fig. 3). These reports, printed in *.pdf files, can be hyperlink. The semantic enrichment with non-geometric data permits to achieve elevated Level of Development, almost LOD 500, 'as built model' for AIA Standard, or LOD E as 'specific model' for the UNI 11337:2017 (Italian Standards).

These attributes might be immediately utilised for next planning phase, in the specific case, structural simulations for better apprehend dynamic behaviour and design consolidation works (i.e. cement injection of walls, installation of tie beams for transversal connection of orthogonal walls). Consequently, structural behaviour (isotropic, orthotropic, anisotropic), mechanical parameters, decay patterns and observations - as derived by BCA - are information requirements for the structural engineering team. These information requirements are computable (physical parameters) and incomputable data (not exported attributes, images, and reports). For this reason, the verification of interoperability among software products can support the investigation about Open Source Standard IFC or other data transfer vehicles (formats, database, server, clouds, etc.).

\subsection{Interoperability Issues}

Focusing on the workflow for planning structural consolidation, structural analysis requests an analytic model (axial lines for mono-dimensional elements and stressed plane of bi-directional bearing elements, nodes, constrains and restrains, and mechanical parameters related to material and section profile) imported or generated into the specific computational tools. The possible solutions to obtain a structural model are essentially two: using the architectural model as reference or converting the model file into a native format for the structural tool. The first option loses the real significance of the interoperability because the structural model 
is re-created following information contained in architectural files. The second method is the most appropriate, even if this procedure can demonstrate some errors and limitations because of operating conversion according to the specification of the receiving software product. The BIM architectural modelling might follow further requirements regarding the preliminary data, such as materials and structural function, and design instruction for building levels. The simplified analysis model becomes structural models adding loads and load-combinations.

The current structural software products work with Revit via IFC format or via plug-ins with losses of BIM object attributes that might be imported manually or semi-automatically as data stored in spreadsheet or tabular database. The verification of interoperability among the BIM design and structural products has been carried out viewing the Revit BIM model (populated with diagnostic data), once exported as IFC transfer file, into the Solibri Model Viewer®, a software product employed to review content data for an effective collaborative process.

The export of the *.ifc file from Revit was set in the version IFC2x3 Coordination View 2.0 (for coordinating architectural, structural and mechanical disciplines). It demonstrates the possibility to partially exchange parameters limited to identification (wall type, discipline, wall stratigraphy without description of materials, envelope function, geometric typology), location, quantities, material (name and thickness), geometry profile, topological connections with the other objects, classification (in this case, Uniformat Standard), and IFC properties (ExtendToStructure, LoadBearing, Reference, ThermalTransmittance), categorized into the property set Pset_WallCommon. Other additional data are automatically exported in IFC opened with ArchiCAD, including type name, structural function, and technical position (envelope), refurbishment phase, all editable, and IFC parameters partially modifiable.

In both the workflows, no information about diagnostic data (images, comments, GPR profiles, mechanical parameters, etc.), inserted into the model, are exchanged. The interoperability issue increases when working on load-bearing masonry walls, in stone bricks.

Whereas, geometrical and topological data are compatible, semantic data about degradation, crack patterns, mechanical parameters and anisotropic structural behaviour of masonry in stone bricks are not recognized. These observations evidence the need to improve nets for synchronized roundtrips between the BIM architectural and structural models.

\section{DISCUSSIONS AND CONCLUSIONS}

Sharing information about diagnostic survey demonstrates criticalities in managing comments, measured values and pictures in a unique model, completely and always accessible. The framework shows the architecture for innovative methods of sharing knowledge and diagnostic data about masonry walls in stone bricks (Fig. 4). Further plug-ins or database for non-BIM data (images, videos, etc.) should be implemented for associating tests acquisitions to alphanumeric data.

The diagnostic results, inserted within Revit, are images correlated by comments about survey methodology, instruments and result interpretations. This data might be shared by database connections to the DBMS (DataBase Management System), working as hardware or software servers. Employing the Revit BIM model as master of data source, attributes can be exported via ODBC (Open DataBase Connectivity) modified and imported into the BIM model. In the current use of Revit as master, diagnostic data might be managed into MS Access, Excel or SQL relational databases creating a form used to input alphanumeric parameters and images, codified, and saved into a standard path. 


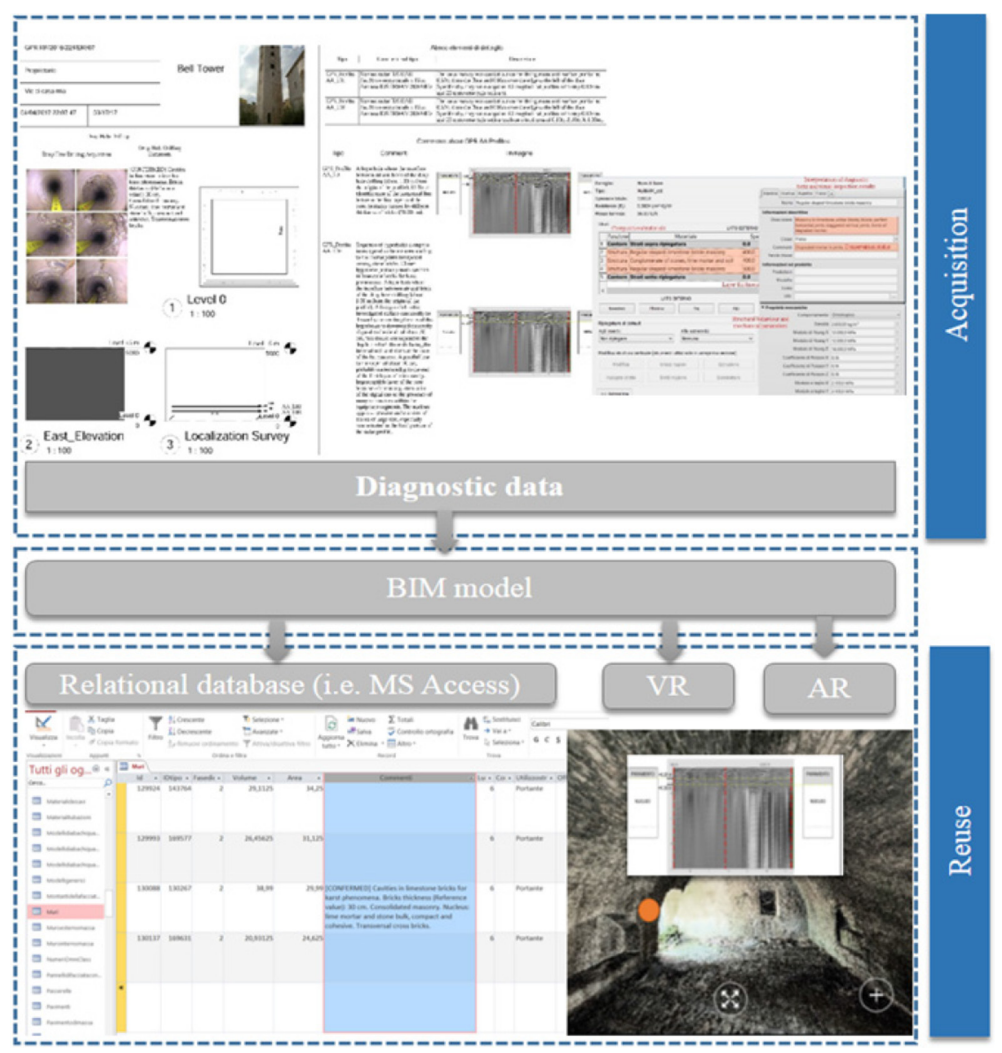

Figure 4: Framework for sharing knowledge about diagnostic data (Source: Authors.)

An alternative solution for knowledge sharing is represented by web services and cloudbased BIM applications. The potentialities of cloud computing technology are emerging for communication devices such as PCs, tablets and smartphones, and its integration with BIM models enhances effective real-time communication platform for project team members [25]. This technology can improve interoperability and project team collaboration in managing data by on-demand access to computing resources and cloud-based applications [26].

A virtual environment, in its immersive or no-immersive utilization, might work on cloudbased or web-based platform for visualizing 3D model content about diagnosis and project, via mobile devices, to have possibilities to receive and use data into the construction field, as a source in remote access. Starting from recent research works about cloud-based VR, for simulating construction site activities, the introduction of non-destructive tests within the virtual environment can represent a benefit for construction collaboration and on site critical decision making [19]. This might enables controlling the development of the construction layout process, with the possibility to keep diagnostic data under control, in order to avoid risks and damages to the high-value architectural elements.

In addition, the Augmented Reality, as a technology to overlap virtual data on the real environment, can assist the utilization of diagnostic acquisitions queried via triggers for transmission of connected information, pre-loaded into the AR application. The integration 
between BIM and AR can occur in two directions: BIM models superimposed on the reality and BIM models upgraded in the AR environment [27]. The merged data can consist in diagnostic values and consolidation works in sequence visualized over the real object to inform professionals and employees about execution. Future efforts might interest the development of a tool for comparing the entire set of diagnostic data and extract with high reliability comments and quantitative data directly employed into a BIM-based decision support system to assist the most coherent and sustainable refurbishment intervention.

\section{ACKNOWLEDGEMENTS}

We thank the B.Re.D srl for making available diagnostic instrumentation and expetises.

\section{REFERENCES}

[1] Vacanas, Y., Themistocleous, K., Agapiou, A. \& Hadjimitsis, D., Building Information Modelling (BIM) and Unmanned Aerial Vehicle (UAV) technologies in infrastructure construction project management and delay and disruption analysis, Third International Conference on Remote Sensing and Geoinformation of the Environment, 9535, 95350C, 2015.

https://doi.org/10.1117/12.2192723

[2] Siebert, S. \& Teizer, J., Mobile 3D mapping for surveying earthwork projects using an Unmanned Aerial Vehicle (UAV) system. Automation in Construction, 41, pp. 1-14, 2014.

https://doi.org/10.1016/j.autcon.2014.01.004

[3] Kanli, A.I., Taller, G., Nagy, P., Tildy, P., Pronay, Z. \& Toros, E., GPR survey for reinforcement of historical heritage construction at fire tower of Sopron. Journal of Applied Geophysics, 112, pp. 79-90, 2015. https://doi.org/10.1016/j.jappgeo.2014.11.005

[4] Yalçıner, C.Ç., Kurban, Y.C. \& Altunel, E., Research using GPR into the cause of cracks and depressions in the floor of the gallery of Hagia Sophia Museum. Construction and Building Materials, 139, pp. 458-466, 2017.

https://doi.org/10.1016/j.conbuildmat.2017.02.036

[5] Succar, B., Building information modelling framework: A research and delivery foundation for industry stakeholders. Automation in Construction, 18, pp. 357-375, 2009.

https://doi.org/10.1016/j.autcon.2008.10.003

[6] Eastman, C., Teicholz, P., Sacks, R. \& Liston, K., BIM handbook: A guide to Building Information Modeling for owners, managers, designers, engineers and contractors, 2nd Edition, 2011.

[7] Eastman, C., Di Giuda, G.M. \& Villa, V., Il BIM : guida completa al Building Information Modeling per committenti, architetti, ingegneri, gestori immobiliari e imprese, Hoepli, 2016.

[8] Meadati, P., Ap, L., Irizarry, J., BIM - A Knowledge Repository, (n.d.), available at http://ascpro.ascweb.org/chair/paper/CERT177002010.pdf (accessed April 18, 2017).

[9] Murphy, M., McGovern, E., Pavia, S., Historic Building Information Modelling - Adding intelligence to laser and image based surveys of European classical architecture. ISPRS Journal of Photogrammetry and Remote Sensing, 76, pp. 89-102, 2013. https://doi.org/10.1016/j.isprsjprs.2012.11.006 
[10] Ciribini, A.L.C., Ventura, S.M. \& Paneroni, M., BIM methodology as an integrated approach to heritage conservation management. WIT Transactions on The Built Environment, 149, pp. 265-276, 2015.

https://doi.org/10.2495/BIM150231

[11] Volk, R., Stengel, J. \& Schultmann, F., Building Information Modeling (BIM) for existing buildings - Literature review and future needs. Automation in Construction, 38, pp. 109-127, 2014. https://doi.org/10.1016/j.autcon.2013.10.023

[12] Bruno, S., De FIno, M. \& Fatiguso, F., HBIM-aided refurbishment process of Cultural Heritage, in: ISTeA-BACK TO 4.0. Rethinking the Digital Construction Industry, pp. 60-69, 2016.

[13] Cho, Y.K., Ham, Y. \& Golpavar-Fard, M., 3D as-is building energy modeling and diagnostics: A review of the state-of-the-art. Advanced Engineering Informatics, 29, pp. 184-195, 2015.

https://doi.org/10.1016/j.aei.2015.03.004

[14] Haugbotn, A., Georadar til utenomhus BIM Prinsipper og praktisk anvendelserA. Haugbotn, Georadar til utenomhus BIM Prinsipper og praktisk anvendelser, in: 2015., in: Konf. 2015 “LØFTER BAE-NÆRINGEN,” 2014.

[15] Oreni, D., Brumana, R., Della Torre, S., Banfi, F., Barazzetti, L. \& Previtali, M., Survey turned into HBIM: The restoration and the work involved concerning The Basilica Di Collemaggio after the earthquake (L'AQUILA). ISPRS Annals of Photogrammetry, Remote Sensing and Spatial Information Sciences, II(5), pp. 267-273. https://doi.org/10.5194/isprsannals-II-5-267-2014

[16] Fai, S., Graham, K., Duckworth, T., Wood, N. \& Attar, R., Building information modelling and heritage documentation, 2011.

[17] Ganah, A. \& John, G.A., Integrating building information modeling and health and safety for onsite construction. Safety and Health at Work, 6, pp. 39-45, 2015. https://doi.org/10.1016/j.shaw.2014.10.002

[18] Crespi, P., Franchi, A., Ronca, P., Giordano, N., Scamardo, M., Gusmeroli, G. \& Schiantarelli, G., From BIM to FEM: the analysis of an historical masonry building. WIT Transactions on The Built Environment, pp. 581-592, 2015. https://doi.org/10.2495/BIM150471

[19] Goulding, J.S., Rahimian, F.P. \& Wang, X., Virtual reality-based cloud BIM platform for integrated AEC projects. Journal of Information Technology in Construction, 19, pp. 308-325, 2014.

[20] Wang, X., Truijens, M., Hou, L., Wang, Y. \& Zhou, Y., Integrating augmented reality with building information modeling: Onsite construction process controlling for liquefied natural gas industry. Automation in Construction, 40, pp. 96-105, 2014. https://doi.org/10.1016/j.autcon.2013.12.003

[21] Park, C.-S., Lee, D.-Y., Kwon, O.-S. \& Wang, X., A framework for proactive construction defect management using BIM, augmented reality and ontology-based data collection template. Automation in Construction, 33, pp. 61-71, 2013. https://doi.org/10.1016/j.autcon.2012.09.010

[22] Kwon, O.-S., Park, C.-S. \& Lim, C.-R., A defect management system for reinforced concrete work utilizing BIM, image-matching and augmented reality. Automation in Construction, 46, pp. 74-81, 2014.

https://doi.org/10.1016/j.autcon.2014.05.005 
[23] Ilter, D. \& Ergen, E., BIM for building refurbishment and maintenance: current status and research directions. Structural Survey, 33, pp. 228-256, 2015.

https://doi.org/10.1108/SS-02-2015-0008

[24] Lee, J., Lee, J., Kim, J.W., Kang, K. \& Lee, M.H., Virtual reconstruction and interactive applications for Korean traditional architectures. SCIRES-IT - Scientific Research and Information Technology, 6, 5-14, 2016. https://doi.org/10.2423/I22394303V6N1P5

[25] Li, H., Wong, J. \& Li, H., A review of cloud-based bim technology in the construction sector. Journal of information Technology in Construction, 19, 281-291, 2014.

[26] Eastman, C.M., Cloud-based BIM Data Transmission: Current Status and Challenges. 33rd International Symposium on Automation and Robotics in Construction. (ISARC 2016), 2016.

[27] Meža, S., Turk, Ž. \& Dolenc, M., Component based engineering of a mobile BIM-based augmented reality system. Automation in Construction, 42, 1-12, 2014. https://doi.org/10.1016/j.autcon.2014.02.011 